\title{
The adherence/resource priming paradigm - a randomised clinical trial conducting a bonafide psychotherapy protocol for generalised anxiety disorder
}

\author{
Christoph Flückiger
}

\begin{abstract}
Background: Bonafide psychotherapy is an effective treatment for generalised anxiety disorder compared to no-treatment. Rather than creating increasing numbers of new overall treatment-packets within a medical meta-model, an additional approach to investigating clinical research designs may be to increase the understanding of already effective psychotherapies. Treatment manuals and protocols allow a relatively high degree of freedom for the way therapists implement the overall treatment manuals. There is a systematic lack of knowledge on how therapists should customise these overall protocols. The present study experimentally examines three ways of conducting a bonafide psychotherapy based on a 15 session time-limited cognitive-behavioural therapy (CBT) protocol and their relation to the therapists' protocol adherence and treatment efficacy.

Methods/design: This trial will investigate three different methods of customising a bonafide CBT-protocol using dyadic peer-tutoring methodology (primings). The individuals with GAD will be randomly assigned to one of three priming conditions (resource priming, supportive resource priming, or adherence priming). The participant treatment allocation will be performed randomly. Therapists will be assigned to a peer-tutoring partner and priming condition based on a mutual agreement. Treatment outcomes will be assessed at the following times: observer based in-session outcomes, session-by-session post-session outcomes, treatment outcome at post assessment and treatment outcome at 6-month follow-up.

Discussion: The proposed trial addresses the clinically relevant question of how to customise a bonafide psychotherapy protocol using tandem peer-tutoring methodology (three priming conditions). Through the development and testing of the proposed priming procedures, this study describes levels of adherence and how to conduct an overall treatment protocol in a more systematised way.
\end{abstract}

Trial registration: From ClinicalTrials.gov Identifier: NCT02039193.

Keywords: Generalised anxiety disorder, Cognitive behaviour therapy, Adherence

Correspondence: christoph.flueckiger@psychologie.uzh.ch

Department of Psychology, University of Zürich, Binzmühlestr. 14/18,

$\mathrm{CH}-8050$ Zürich, Switzerland 


\section{Background}

In European countries, the lifetime prevalence of generalised anxiety disorder (GAD) varies from 5 to $10 \%$ [1-5]. Uncontrollable worrying as a primary symptom of GAD constitutes a maladaptive cognitive strategy to avoid experiencing anxiety [6,7] and emotional states in general $[8,9]$. Individuals with GAD show deficits in detecting and regulating emotional states, which may accelerate a positive feedback circuit between general stress symptoms and pathological worrying [10-12]. Finally, experiential avoidance may lead to a restriction in proactive behaviours as individuals become focused on avoiding events and situations rather than pursuing activities that are consistent with their personal values $[13,14]$, which may be related to the hypersensitivity of the Behavioural Inhibition System seen in individuals with GAD [15].

Bonafide psychotherapy is an effective treatment for GAD compared to no-treatment and treatment as usual [16-18], but also more generally for individuals that suffers from anxiety and depression [19]. For cognitive-behavioural therapy (CBT), there are a number of treatment manuals/ protocols, e.g. psycho education, relaxation techniques, cognitive restructuring of (meta-) cognitions, (imagery-) exposure, and in vivo confrontation, that primarily reference standard techniques to correct and compensate GAD symptoms [20-24]. In addition, strengths-oriented strategies aim to capitalise on the patient's pre-existing resources, such as the patient's individual and interpersonal abilities and readiness. Such strategies, e.g. acceptance strategies [25], motivational interviewing [26], and well-being therapy [27] and, more generally, solution-focused interventions [28], positive interventions [29], resilience-focused interventions [30] and resource-oriented approaches [31-34], have recently been discussed for GAD treatment. Such strengths-oriented tools, however, may be based on more general counselling and consulting psychology principles, such as making hope explicit $[35,36]$ or understanding the client's functional behaviours [37-39].

The separation into compensation- and capitalisationoriented strategies probably a false dichotomy, and psychotherapy (socratic) dialogues often simultaneously respond to the participants' targeted weaknesses and strengths in general [40-43] but also to GAD more specifically [44]. Psychotherapy dialogues can be seen as a highly interactive and responsive treatment through which therapists and patients work together to achieve well-specified treatment goals that take into consideration the patients' entire living environment, including strengths and weaknesses [45-47].

Rather than creating increasing numbers of new overall treatment-packets within a medical meta-model, an additional approach to investigating clinical research designs may be to increase the understanding of already effective psychotherapies [45,48-50]. Moreover, psychotherapy research is moving from legitimation- and competition-oriented investigations to more comprehensionoriented process-outcome based research [51]. Treatment manuals and protocols allow a relatively high degree of freedom for the way therapists implement the overall treatment manuals. There is a systematic lack of knowledge on how therapists should customise these overall protocols $[31,52,53]$. The present study experimentally examined three ways of conducting a cognitive-behavioural therapy (CBT) protocol and their relation to the therapists' protocol adherence and treatment efficacy.

\section{Aims of the trial}

This trial will investigate three different methods of customising bonafide psychotherapy based on a wellintroduced CBT-protocol by Zinbarg, Craske and Barlow [24] using dyadic peer-tutoring methodology (primings). The participants will be randomly assigned to three priming conditions: (a) adherence priming; (b) resource priming or (c) supportive resource priming $[32,39]$.

The main research questions are as follows:

(1) In-session outcomes. Using videotapes, observerbased video analyses will be conducted: (a) Do the resource priming conditions show comparable observer-based adherence of the therapist in comparison to the adherence priming condition [54]? (b) Do the resource priming conditions result in more resource-activating micro-interventions than the adherence priming condition [55]? (c) Are the in-session processes predictors and mediators of session and therapy outcomes [43]?

(2) Post-session outcomes. Are there differences in the post-session outcomes for the 3 different priming conditions? Furthermore, are the post-session outcomes also symptom change predictors and mediators of therapy outcome [56]?

(3) Treatment outcomes. Do the resource priming conditions have comparable efficacy on GAD outcomes, general outcomes and dropout rates in comparison to the adherence priming condition?

\section{Methods/design}

This study is a randomised controlled trial with three active treatment arms. This trial will be conducted at the Swiss psychotherapy outpatient clinic in the Department of Psychology at the University of Zürich. Figure 1 depicts the $3 \times 4$ design with one between-subject factor (resource priming, supportive resource priming, or problem priming) and one within-subject factor (time: pre, mid, post, or follow-up). 


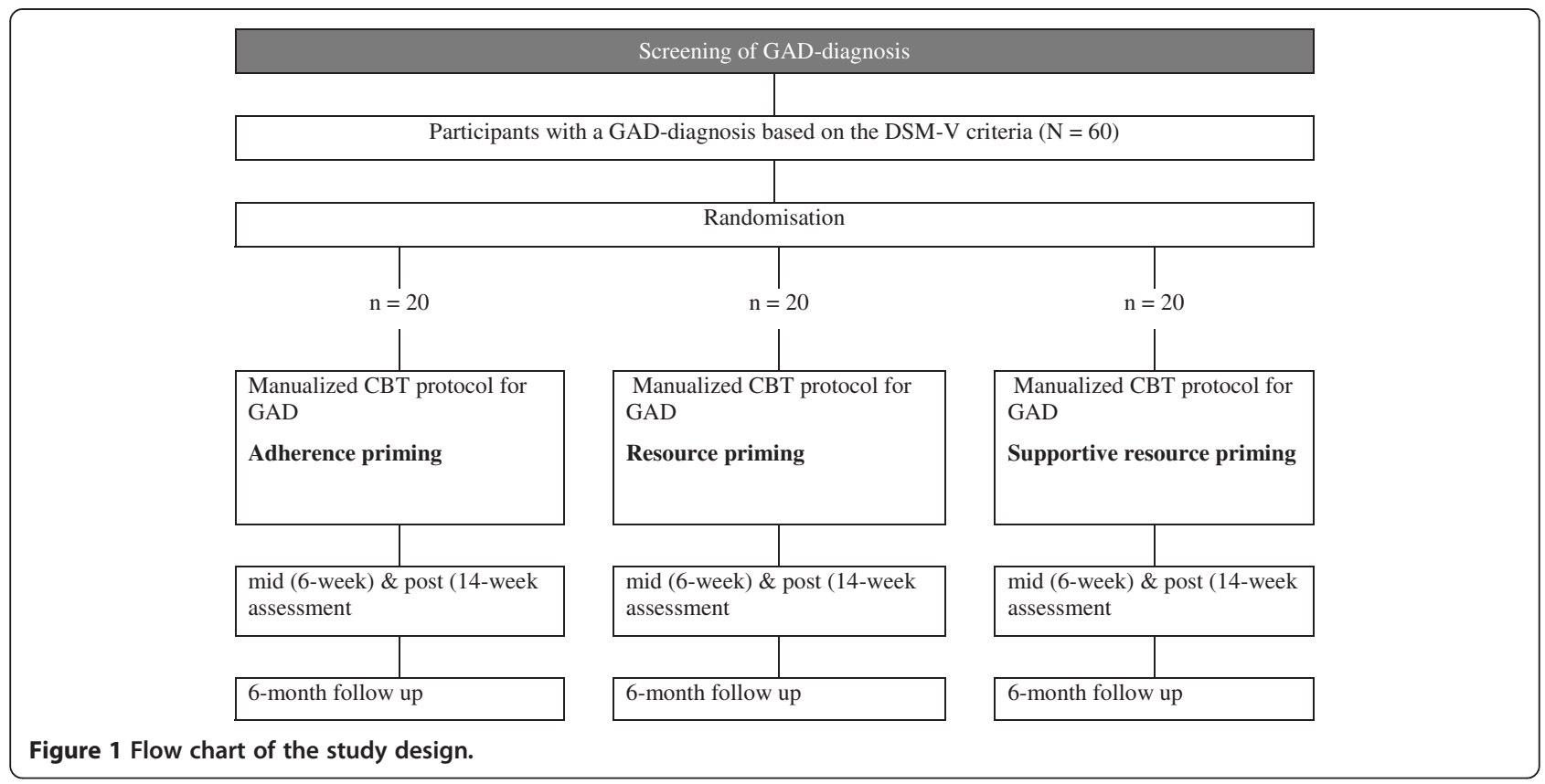

\section{Participants}

\section{Inclusion/exclusion criteria}

Participants will be included in the study if they: (a) are 18 years of age or older; (b) agree to the informed consent, (c) have sufficient knowledge of German; and (d) and fulfil the diagnostic criteria of GAD DSM-IV. Participants will be excluded for the following reasons: (a) they have a score of 2 or higher on the suicide item of the BDI and/or are found to have active suicidal plans during the diagnostic screening interview, (b) they are currently taking a psychotic or bipolar disorder medication, or (c) they are currently receiving treatment from a professional psychotherapist. Prescribed medications for anxiety or depressive disorders do not lead to exclusion from the study, if the dosage has remained constant for at least one month. The presence of comorbidities does not result in exclusion from the study, if GAD is in the foreground according to the severity rating of the Diagnostic Interview for DSM-diagnoses.

\section{Recruitment}

Participants will be recruited by means of advertisements in newspapers and through internet forums. High-circulation newspapers are delivered for free through the Swiss public transport system. Individuals interested in participating in the study will contact the study office via SMS, e-mail or phone. Positively screened patients will be invited for an intake assessment to determine whether they will be included or excluded using a standardised interview. Participants that are not screened positively will be informed of more appropriate treatments via a phone call or, if requested, a face-to-face contact.

\section{Randomisation and treatment allocation}

After meeting the inclusion criteria, patients will be randomly assigned to one of the three conditions (adherence priming, resource priming, or supportive resource priming). Treatment allocation is performed using an online application for full randomisation. In this way, we aim to ensure that the trial arms are balanced with respect to the patients' baseline characteristics. Randomisation will be conducted by two independent research assistants. Because all patients will be treated using the same CBT-manual, patients are blinded to their treatment allocation and are not informed about the randomisation procedure.

\section{GAD treatment protocol}

CBT-manual by Zinbarg, Craske and Barlow (MAWpacket) [24]: CBT for GAD typically consists of psychoeducation of generalised anxiety disorder, relaxation training (RT), cognitive restructuring (CR) and some invivo situational exposure for patients with overt behavioural avoidance [20,22]. Furthermore, imagery exposure as a GAD-specific form of in-sensu exposition will be applied to reduce experiential avoidance. The manualized therapy follows a usual treatment format of 14 50minute sessions and a booster session after 6 months (15 sessions in total).

\section{Tandem peer-tutoring (priming)}

To investigate various methods of conducting a standardised CBT-protocol, all therapists are tutored in peer dyads (tandem peer-tutoring). Immediately before sessions 1 to 5 , the therapists are required to contact the 
tandem-partner face-to-face or on the phone to discuss the upcoming session in a 5 to 10 minute brief conversation (primings; for a comparable procedure see Flückiger and Grosse Holtforth [32]). There are three tandem peer-tutoring conditions:

(1) Adherence priming: Immediately before sessions 1 to 5 , a therapist conducts five-minute conversation about how to implement the disorder-specific interventions that are described in the treatment protocol. These communications are focused on the therapist's understanding of the patients GAD and any related comorbidities and how those issues can be addressed in the prescriptive treatment protocol.

(2) Resource priming: Immediately before sessions 1 to 5, a therapist conducts a five-minute conversation with the participant about how to implement strengthsbased micro-interventions in the upcoming session. Strengths-based micro-interventions allow therapists to focus on a patient's pre-existing strengths and abilities, subtle changes and improvements to those strengths and abilities during therapy (potential resources), and motivational preparedness, readiness and goals (motivational resources) [39,57].

(3) Supportive resource priming: The supportive resource priming condition uses the same protocol as the resource priming condition (5 brief tandem peer-tutorings). The only difference in the procedure is that the therapists are allowed to integrate a helpful significant person from the patients entourage (such as a partner or best friend) during sessions 1 and 7 to encourage them to support the patient in adhering to their treatment plan (active integration of interpersonal resources). However, the integration of a significant person does not affect the CBT-treatment protocol.

\section{Therapists}

Twelve advanced trainees with at least 2 years postgraduate training will be recruited from local psychotherapy-training centres. The majority of those therapists have experience as study therapists in a prior randomised controlled trial (ClinicalTrials.gov Identifier: NCT01012856). All of the therapists will participate in an initial 16-hour workshop presented by the (co-)developer of the treatment manual (Zinbarg) [24]. In addition to the peer-tutoring (primings), the therapists will be regularly supervised in small groups on a 14-day basis. The supervision is conducted in mixed groups for all three priming conditions. All of the supervisors also participate in the initial 16-hour workshop. To respect and coordinate the therapists' preferences (e.g., preferences in working days and time schedules) they will be assigned in a joint face-to-face session at the beginning of the study. All of the therapists will give verbal and written consent for their selected peertutoring partner and priming condition. To control for potential effects of particular therapists, we will investigate the therapists' self-reported interpersonal strengths and problems, their attachment quality and their therapeutic attitudes along with their allegiance to the underlying CBTprotocol.

\section{Assessments}

For an overview of the assessments see Table 1. At intake, GAD-diagnosis and its core symptomatology will be identified according to the structured interview section for GAD (DIPS; [58]). Furthermore, GAD-criteria are assessed using self-reports. The individual worries are identified using the Penn State Worry Questionnaire (PSWQ; $[59,60]$ ) and the Worry Domain Questionnaire (WDQ; [60,61]). Mental disorders on Axis I and II are assessed using face-to-face diagnostic interviews (Strukturiertes Klinisches Interview für DSM, SKID-I/II; [62]).

The PSWQ, Beck Anxiety Inventory (BAI; [63,64]) and the State-Trait Anxiety (STAI; $[65,66])$ questionnaire will used to measure GAD-outcomes. Premature termination from the trial, interpersonal problems and strengths inventories, general symptom severity, the behavioural inhibition and activation scale, as well as the resource potential questionnaire will be used to measure general outcomes (see Table 1). The outcome measures are taken at intake, directly after session 6 (end of primings), session 14 (postassessment), and at the 6-month follow-up.

The following process measures are examined: (a) Postsession reports: alliance [78,79], post-session outcomes [80] and symptom change are conducted based on a session-bysession assessment from session 1 to 15 and (b) In-session processes: using the recorded videotapes, adherence ratings for the CBT-program [54], the Resource-Oriented Microprocess Analysis (ROMA-P/T; [55]) and the level of explication scale by Sachse [81] are conducted at sessions 2, 5 and 8 .

\section{Study from the participants view}

After contacting the study administration, the information given to the participants will contain a precise description of the inclusion and exclusion criteria, the structure of the treatment manual as well as the data collection procedure, including the procedure for the videorecordings (Figure 2). Confidentiality of the collected data will be confirmed. Voluntariness of participation will be emphasised by explaining the opportunity to terminate the treatment at every timepoint during treatment and the opportunity to cancel the use of any data collected. Furthermore, an insurance policy for possible negative outcomes resulting from participation in clinical trials will be contracted. 
Table 1 Schedule of measures

\begin{tabular}{|c|c|c|c|c|c|c|}
\hline \multirow[t]{2}{*}{ Measures } & \multicolumn{6}{|c|}{ Measurement waves } \\
\hline & Ass. & Pre & Sess-by-Sess & Mid & Post & FU \\
\hline \multicolumn{7}{|l|}{ Eligibility } \\
\hline Structured Interview for DSM (SCID) [62] & + & & & & & \\
\hline GAD-section of the (F-DIPS) [58] & + & & & & & \\
\hline GAD-criteria self-report [62] & + & & & & & \\
\hline WDQ $[60,61]$ & + & & & & & \\
\hline \multicolumn{7}{|l|}{ GAD-outcomes } \\
\hline Beck Anxiety Inventory (BAI) [63,64] & & + & $1-15$ & + & + & + \\
\hline Penn State Worry Questionnaire (PSWQ) $[59,60]$ & + & + & & + & + & + \\
\hline State -Trait Anxiety (STAI) $[65,66]$ & & + & & + & + & + \\
\hline \multicolumn{7}{|l|}{ General-outcomes } \\
\hline Premature termination & & & $1-15$ & & & \\
\hline Beck Depression Inventory II (BDI-II) [67,68] & + & + & & + & + & + \\
\hline Brief Symptom Inventory (BSI) $[69,70]$ & & + & & + & + & + \\
\hline BIS/BAS scales [71,72] & & + & & + & + & + \\
\hline Inventory of Interpersonal Problems (IIP-64) [73,74] & & + & & + & + & + \\
\hline Inventory of Interpersonal Strengths (IIS-64) [75,76] & & + & & + & + & + \\
\hline Resource potential questionnaire (RES) $[75,77]$ & & + & & + & + & + \\
\hline \multicolumn{7}{|l|}{ Self-report process-measures } \\
\hline Working Alliance Inventory - Patient (WAI-P) [78,79] & & & $1-15$ & & & \\
\hline Working Alliance Inventory - Therapist (WAI-T) [78,79] & & & $1-15$ & & & \\
\hline Bern Post-Session Report - Patient (BPSR-P) [80] & & & $1-15$ & & & \\
\hline Bern Post-Session Report - Therapist (BPSR-T) [80] & & & $1-15$ & & & \\
\hline \multicolumn{7}{|l|}{ Video observer ratings } \\
\hline Adherence rating & & & $2,5,8,11$ & & & \\
\hline Resource-oriented Microprocess Analysis - Patient (ROMA-P) [55] & & & $2,5,8,11$ & & & \\
\hline Resource-oriented Microprocess Analysis - Therapist (ROMA-T) [55] & & & $2,5,8,11$ & & & \\
\hline Level of explication [81] & & & $2,5,8,11$ & & & \\
\hline \multicolumn{7}{|l|}{ Therapists' measures } \\
\hline Inventory of Interpersonal Problems (IIP-64) [73,74] & $++_{1}$ & & & & & \\
\hline Inventory of Interpersonal Strengths (IIS-64) [75,76] & $+_{1}$ & & & & & \\
\hline Measure of Attachment Quality (MAQ) $[82,83]$ & $+{ }_{1}$ & & & & & \\
\hline Therapists' allegiance self-report & $+_{1}$ & & & & & \\
\hline Therapeutic Attitude Scale (TASC), therapeutic style section [84] & & & & & $+_{2}$ & \\
\hline
\end{tabular}

${ }_{1} A t$ the beginning of the study, ${ }_{2} A t$ the overall end of the treatment.

\section{Statistical analysis}

To handle the hierarchical data structures (sessions at level 1 nested within patients at level 2 and therapists at, level 3), a hierarchical linear model (HLM) with time as a within-groups factor and the treatment condition as a between-groups factor will be used for the main research questions [85]. The analyses will be conducted on the intention-to-treat sample as well as on the completer sample. To investigate if patients and therapists have effects on the therapy outcomes, the patients' and therapists' pre-treatment characteristics will be investigated as outcome predictors at levels 2 and 3.

\section{Sample size}

Based on a power analysis with G*Power [86], the optimal sample size with an Alpha-error of 5\%, a Beta-error of $80 \%$ and a correlation coefficient for the repeated assessments of of $r=.30$ is 60 participants, i.e., 20 participants in each priming condition. 


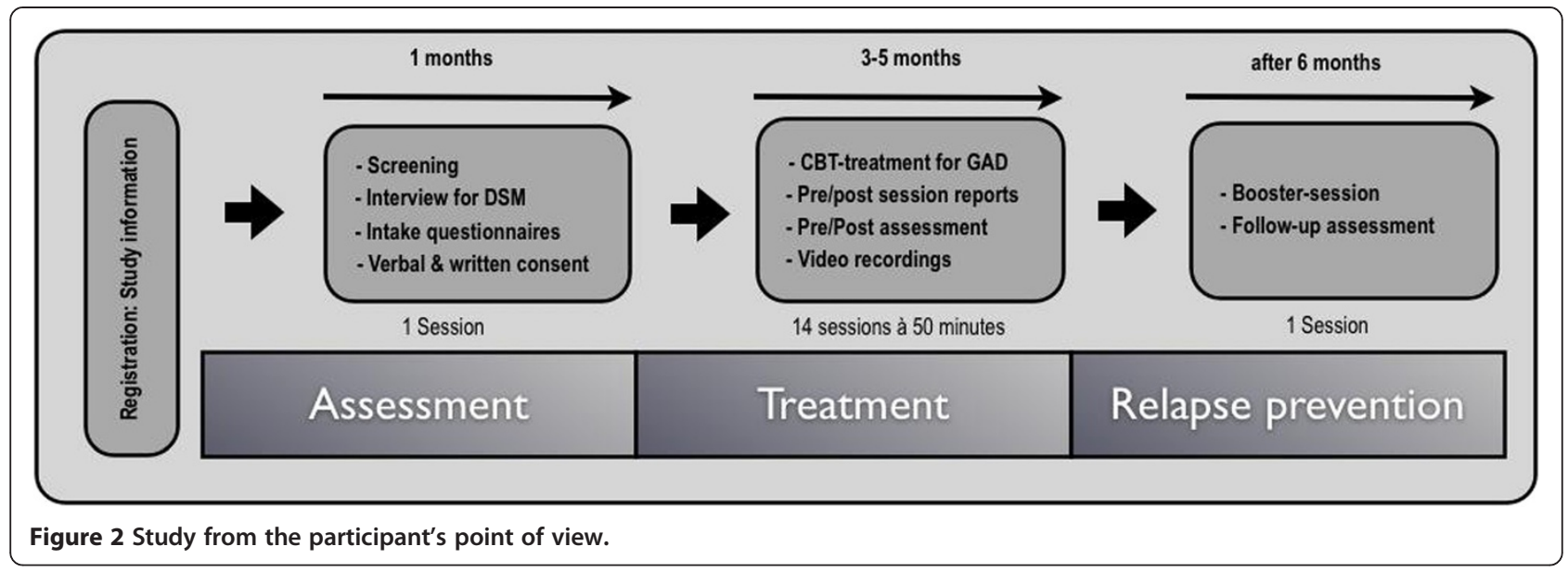

\section{Ethical review}

This study protocol is approved by the Ethical Committee of Canton Zurich (KEK 2011-0475) and the Ethical Committee of the Philosophical Faculty of University of Zurich (PhiF-EK_20.1.2012).

\section{Discussion}

Bonafide psychotherapy is an effective treatment for individuals who suffer from GAD and its comorbidities in comparison to no-treatment and treatment as usual $[16,17,18]$. Rather than creating increasing numbers of new overall treatment-packets within a medical meta-model, an additional approach may be to increase the understanding of already effective psychotherapies [45,48-50]. The psychotherapy field is moving from legitimation and competition focused research to a more comprehensionoriented process-outcome research methodology [47,51]. Treatment manuals and protocols allow a relatively high degree of freedom for the way therapists implement the treatment protocols. The present design experimentally examines the therapists' within-protocol variability and its relation to treatment outcome. More specifically, three methods of conducting the same treatment protocol are compared to each other using tandem peer-tutoring methodology (resource priming, supportive resource priming, and adherence priming).

The hierarchical structure of the design allows the simultaneous examination of the patients' contributions and the therapists' contributions. In contrast to double blinded medication trials, therapists' and patients' are informed and actively involved in the psychotherapeutic treatment plans. This involvement is not a bias that has to be eliminated and it might be well an active ingredient of a successful psychotherapy that the therapists' and patients' take a proactive, responsive role in the treatment $[37,87]$. The present design allows for the experimental investigation of some potentially meaningful aspects of this proactive variability.

\section{Bias minimization}

Participants

Patients will be randomly assigned to conditions in order to reduce potential biases of participant characteristics. The inclusion and exclusion criteria allow for a relatively homogeneous group of individuals; the primary GAD diagnoses, comorbidities with substance use disorders and severity of depression along with age, sex and gender will be tested as potential confounders.

In traditional psychotherapy trials, where two or more treatments protocols are compared to each other, the patients' are informed about the various randomised treatment conditions of the active treatments (e.g., psychotherapy vs. waiting list). In the present trial, the patients' are treated with the same treatment protocol, and, thus the randomisation procedure essentially does not affect the overall treatment plan. Referring to the preexisting standards, the patients can be blinded to the randomised therapist conditions in order to reduce potential biases from the outcome expectations of the patients.

\section{Therapists}

A potential bias due to allegiances of the therapists is a concern, especially in human treatments where inductions of outcome expectations can be problematic. To minimise this potential bias, therapists will be allocated to the peertutoring partners based on common consent. Furthermore, they will be supervised in mixed groups, where the priming condition plays no explicit role and the supervisors are advised to focus on therapist skills independent of the underlying priming conditions. Nonetheless, because the therapists are informed about the treatment protocol, the allegiances of the therapists to specific CBT protocols will be declared and considered in the statistical analyses.

Keeping the above mentioned strengths and limitations of the present design in mind, the proposed trial addresses the clinically relevant question of how to customise a 
bonafide psychotherapy using tandem peer-tutoring methodology (three priming conditions). Through the development and testing of the proposed priming procedures, the study could potentially define levels of adherence for conducting an overall treatment protocol more appropriately $[52,88]$.

\section{Competing interests}

The author declares that he has no competing interests.

\section{Authors' contributions}

CF is the principal investigator running the study primary over a period of 3 years.

\section{Acknowledgements}

This study is funded by the Swiss National Science Foundation (SNSF PZ00P1_136937/1).

Received: 23 January 2014 Accepted: 14 February 2014 Published: 20 February 2014

\section{References}

1. Angst J: Modern epidemiology of anxiety: results of the Zurich cohort study. Hum Psychopharm Clin 1999, 14:S29-S37.

2. Angst J, Gamma A, Baldwin DS, Ajdacic-Gross V, Rössler W: The generalized anxiety spectrum: prevalence, onset, course and outcome. Eur Arch Psy Clin N 2009, 259(1):37-45.

3. Hoyer J, Beesdo K, Becker ES, Wittchen H-U: Epidemiologie und nosologischer Status der Generalisierten Angststörung. Z Klin Psychol Psychother 2003, 32(4):267-275.

4. Lieb R, Becker E, Altamura C: The epidemiology of generalized anxiety disorder in Europe. Eur Neuropsychopharmacol 2005, 15(4):445-452.

5. Wittchen H-U, Zhao S, Kessler RC, Eaton WW: DSM-III-R generalized anxiety disorder in the National Comorbidity Survey. Arch Gen Psychiatry 1994 51(5):355-364.

6. Borkovec TD: The nature, functions, and origins of worry. In Worrying: Perspectives on theory, assessment, and treatment. Edited by Davey GCL, Tallis F. Oxford, England: Wiley; 1994:5-33.

7. Borkovec TD, Alcaine O, Behar ES: Avoidance theory of worry and generalized anxiety disorde. In Generalized anxiety disorder: Advances in research and practice. Edited by Heimberg R, Mennin D, Turk C. New York, NY: Guilford; 2004:77-108.

8. Newman MG, Llera SJ: A novel theory of experiential avoidance in generalized anxiety disorder: a review and synthesis of research supporting a contrast avoidance model of worry. Clin Psychol Rev 2011, 31(3):371-382

9. Roemer $L$, Salters K, Raffa S, Orsillo S: Fear and avoidance of internal experiences in GAD: preliminary tests of a conceptual model. Cogn Ther Res 2005, 29(1):71-88.

10. Mennin DS, Heimberg RG, Turk CL, Fresco DM: Applying an emotion regulation framework to integrative approaches to generalized anxiety disorder. Clin Psychol Sci Pract 2002, 9(1):85-90.

11. Mennin DS, McLaughlin KA, Flanagan TJ: Emotion regulation deficits in generalized anxiety disorder, social anxiety disorder, and their cooccurrence. J Anxiety Disord 2009, 23(7):866-871.

12. Turk $C L$, Heimberg RG, Luterek JA, Mennin DS, Fresco DM: Emotion dysregulation in generalized anxiety disorder: a comparison with social anxiety disorder. Cogn Ther Res 2005, 29(1):89-106.

13. Michelson SE, Lee JK, Orsillo SM, Roemer L: The role of values-consistent behavior in generalized anxiety disorder. Depress Anxiety 2011, 28(5):358-366.

14. Roemer L, Orsillo SM: Expanding Our conceptualization of and treatment for generalized anxiety disorder: integrating mindfulness/acceptancebased approaches with existing cognitive-behavioral models. Clin Psychol Sci Pract 2002, 9(1):54-68.

15. Maack DJ, Tull MT, Gratz JL: Examining the incremental contribution of behavioral inhibition to generalized anxiety disorder relative to other Axis I disorders and cognitive-emotional vulnerabilities. J Anxiety Disord 2012, 26:689-695.
16. Cuijers P, Sijbradij M, Koole S, Huibers M, Berking M, Andersson G: Psychological treatment of generalized anxiety disorder: A meta analysis. Clin Psychol Rev 2014, 34(2):130-140.

17. Mitte K: Meta-analysis of cognitive-behavioral treatments for generalized anxiety disorder: a comparison with pharmacotherapy. Psychol Bull 2005, 131(5):785-795.

18. Hanrahan F, Field AP, Jones GW, Davey GCL: A meta-analysis of cognitive therapy for worry in generalized anxiety disorder. Clin Psychol Rev 2013, 33:120-132.

19. Wampold BE, Budge SL, Laska KM, Del Re AC, Baardseth TP, Flückiger C Minami T, Kivlighan DMI, Gunn W: Evidence-based treatments for depression and anxiety versus treatment-as-usual: a meta-analysis of direct comparisons. Clin Psychol Rev 2011, 31:1304-1312.

20. Barlow DH, Rapee RM, Brown TA: Behavioral treatment of generalized anxiety disorder. Behav Ther 1992, 23(4):551-570.

21. Beck AT, Emery G, Greenberg RL: Anxiety disorders and phobias a cognitive perspective. New York: Basic Books; 1985

22. Borkovec TD, Costello E: Efficacy of applied relaxation and cognitive-behavioral therapy in the treatment of generalized anxiety disorder. J Consult Clin Psychol 1993, 61(4):611-619.

23. Wells A: A metacognitive model and therapy for generalized anxiety disorder. Clin Psychol Psychother 1999, 6(2):86-95.

24. Zinbarg RE, Craske MG, Barlow DH: Mastery of Your Anxiety and Worry (MAW): Therapist Guide: Therapist Guide. New York: Oxford University Press; 2006.

25. Roemer L, Orsillo SM, Salters-Pedneault K: Efficacy of an acceptance-based behavior therapy for generalized anxiety disorder: evaluation in a randomized controlled trial. J Consult Clin Psychol 2008, 76(6):1083-1089.

26. Westra HA, Arkowitz H, Dozois DJA: Adding a motivational interviewing pretreatment to cognitive behavioral therapy for generalized anxiety disorder: a preliminary randomized controlled trial. J Anxiety Disord 2009, 23(8):1106-1117.

27. Fava GA, Ruini C, Rafanelli C, Finos L, Salmaso L, Mangelli L, Sirigatti S: Well-being therapy of generalized anxiety disorder. Psychother Psychosom 2005, 74(1):26-30.

28. Knekt $\mathrm{P}$, Lindfors $\mathrm{O}$, Härkänen $\mathrm{T}$, Välikoski $\mathrm{M}$, Virtala $\mathrm{E}$, Laaksonen $M A$ Marttunen M, Kaipainen M, Renlund C: Randomized trial on the effectiveness of long-and short-term psychodynamic psychotherapy and solution-focused therapy on psychiatric symptoms during a 3-year follow-up. Psychol Med 2008, 38(05):689-703.

29. Rashid T: Positive interventions in clinical practice. J Clin Psychol 2009, 65(5):461-466

30. Padesky CA, Mooney KA: Strengths-based cognitive-behavioural therapy: a four-step model to build resilience. Clin Psychol Psychother 2012, 19(4):283-290.

31. Cheavens JS, Strunk DR, Lazarus SA, Goldstein LA: The compensation and capitalization models: a test of two approaches to individualizing the treatment of depression. Behav Res and Therapy 2012, 50(11):699-706.

32. Flückiger C, Grosse Holtforth M: Focusing the therapist's attention on the patient's strengths: a preliminary study to foster a mechanism of change in outpatient psychotherapy. J Clin Psychol 2008, 64(7):876-890.

33. Willutzki U, Neumann B, Haas H, Koban C, Schulte D: Zur Psychotherapie sozialer Ängste: Kognitive Verhaltenstherapie im Vergleich zu einem kombiniert ressourcenorientierten Vorgehen. Z Klin Psychol Psychother 2004, 33(1):42-50.

34. Teismann T, Dymel W, Schulte D, Willutzki U: Ressourcenorientierte akutbehandlung unipolarer depressionen. Eine randomisierte kontrollierte psychotherapiestudie. Psychother Psychosom Med Psychol 2011, 2011(61):295-302.

35. Snyder CR, Taylor JD: Hope as a common factor across psychotherapy approaches: a lesson from the "Dodo's Verdict.". In Handbook of hope: Theory, measures, and applications. 1st edition. Edited by Snyder CR. San Diego, CA: Academic Press; 2000:89-108

36. Wampold BE, Budge SL: The 2011 leona tyler award address: the relationship-and its relationship to the common and specific factors of psychotherapy. Couns Psychol 2012, 40:601-623.

37. Bohart AC, Tallman K: How clients make therapy work the process of active self-healing. Washington, DC: American Psychological Association; 1999.

38. Bugas J, Silberschatz G: How patients coach their therapists in psychotherapy. Psychotherapy 2000, 37(1):64-70. 
39. Flückiger C, Wüsten G, Zinbarg RE, Wampold BE: Resource activation - Using Clients' Own Strengths in Psychotherapy and Counseling. Cambridge, MA: Hogrefe; 2010.

40. Gassmann D, Grawe K: General change mechanisms: the relation between problem activation and resource activation in successful and unsuccessful therapeutic interactions. Clin Psychol Psychother 2006, 13(1):1-11.

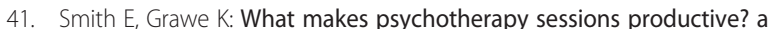
new approach to bridging the gap between process research and practice. Clin Psychol Psychother 2003, 10(5):275-285.

42. Smith E, Grawe K: Which therapeutic mechanisms work when? A step towards the formulation of empirically validated guidelines for therapists' session-to-session decisions. Clin Psychol Psychother 2005, 12(2):112-123.

43. Flückiger C, Caspar F, Grosse Holtforth M, Willutzki U: Working with patients' strengths: a microprocess approach. Psychother Res 2009, 19(2):213-223.

44. Flückiger C, Zinbarg RE, Znoj H, Ackert M: Resource activation in generalized anxiety - an observer-based microprocess analysis of Patients' in-session oosijoutcomes. Psychotherapy 2013. 10.1037/a0034119.

45. Wampold BE: The Great Psychotherapy Debate: Models, Methods, and Findings. Taylor \& Francis Group: New York, NY; 2001.

46. Stiles WB: Responsiveness as an obstacle for psychotherapy outcome research: It's worse than You think. Clin Psycho/ Sci Pract 2009, 16(1):86-91.

47. Norcross JC: Psychotherapy Relationships That Work: Evidence-Based Responsiveness. 2nd edition. New York, NY: Oxford University Press; 2011.

48. Grawe K: Research-informed psychotherapy. Psychother Res 1997, 7(1):1-19.

49. Wampold BE: Psychotherapy: the humanistic (and effective) treatment. Am Psychol 2007, 62(8):857-873.

50. American Psychological Association - APA: Recognition of psychotherapy effectiveness. Psychotherapy 2013, 50:102-109.

51. Lambert MJ: Introduction and Historical Overview. In Bergin and Garfield's Handbook of Psychotherapy and Behavior Change. 6th edition. Edited by Lambert MJ. Hoboken, NJ: Wiley; 2013.

52. Webb CA, DeRubeis RJ, Barber JP: Therapist adherence/competence and treatment outcome: a meta-analytic review. J Consult Clin Psychol 2010, 78:200-211.

53. Eells TD, Lombart KG, Kendjelic EM, Turner LC, Lucas CP: The quality of psychotherapy case formulations: a comparison of expert, experienced, and novice cognitive-behavioral and psychodynamic therapists. $J$ Consult Clin Psychol 2005, 73:579-589.

54. Zinbarg RE, Eun Lee J, Lira Yoon K: Dyadic predictors of outcome in a cognitive-behavioral program for patients with generalized anxiety disorder in committed relationships: a "spoonful of sugar" and a dose of non-hostile criticism may help. Behav Res Ther 2007, 45(4):699-713.

55. Flückiger C, Grosse Holtforth M: Ressourcenorientierte Mikroprozess Analyse (ROMA) - Ressourcendiagnostik und Ressourcenaktivierung im Therapieprozess. Zeitschrift für Klinische Diagnostik und Evaluation 2008, 1(2):171-185.

56. Flückiger C, Grosse Holtforth M, Znoj HJ, Caspar F, Wampold BE: Is the relation between early post-session reports and treatment outcome an epiphenomenon of intake distress and early response? A multi-predictor analysis in outpatient psychotherapy. Psychother Res 2013, 23:1-13.

57. Grawe K: Neuropsychotherapy: how the neurosciences inform effective psychotherapy. Mahwah, NJ: Lawrence Erlbaum; 2006

58. Margraf J, Schneider S, Ehlers A: Diagnostisches Interview bei Psychischen Störungen (DIPS). Berlin, Germany: Springer; 1991.

59. Meyer TJ, Miller ML, Metzger RL DBT: Development and validation of the penn state worry questionnaire. Behaviours Research and Therapy 1990, 28:487-495.

60. Stöber J: Besorgnis: Ein Vergleich dreier Inventare zur Erfassung allgemeiner Sorgen. Zeitschrift für Differentielle und Diagnostische Psychologie 1995, 16:50-63.

61. Tallis F, Eysenck MW, Mathews A: WDQ. Questionnaire for the measurement of non-pathological worry. Personality and Individividual Differences 1992, 23:161-168.

62. Wittchen H-U, Zaudig M, Fydrich T: SKID. Strukturiertes Klinisches Interview für DSM-IV Achse I und II Handanweisung. Göttingen, Germany: Hogrefe; 1997.

63. Beck AT, Epstein N, Brown G, Steer RA: An inventory for measuring clinical anxiety: psychometric properties. J Consult Clin Psychol 1988, 56:893-897.
64. Margraf J, Ehlers A: BAI. Beck-Angstinventar. Hartcourt: Frankfurt, Germany; 2007.

65. Spielberger CD, Gorssuch RL, Lushene PR, Vagg PR, Jacobs GA: Manual for the State-Trait Anxiety Inventory (STAI). Palo Alto, CA: Consulting Psychologist Press; 1983.

66. Laux L, Glanzmann P, Schaffner P, Spielberger CD: State-Trait-Angstinventar (STAl). Beltz: Weinheim, Germany; 1981.

67. Beck AT, Steer RA KBG: BDI-II, Beck Depression Inventory. Boston: Harcourt, MA; 1996.

68. Hautzinger M, Keller F, Kühner C: BDI-II. Beck-Depressions-Inventor Revision. Pearson Assessment: Frankfurt, Germany; 2009

69. Derogatis LR: BSI Brief Symptom Inventory: Administration, Scoring, and Procedure Manual. Minneapolis, NN: National Computer Systems; 1993.

70. Franke GH: Brief Symptom Inventory von L. R. Derogatis (Kurzform der SCL-90R) -Deutsche Version. Beltz: Weinheim, Germany; 2000

71. Carver CS, White TL: Behavioral inhibition, behavioral activation, and affective responses to impending reward and punishment: The BIS/BAS scales. J Pers Soc Psychol 1994, 67:319-333.

72. Strobel A, Beauducel A, Debener S, Brocke B: Eine deutschsprachige Version des BIS/BAS-Fragebogens von Carver und White. Zeitschrift für Differentielle und diagnostische Psychologie 2001, 22:216-227.

73. Horowitz LM, Rosenberg SE, Baer BA, Ureño G, Villaseñor VS: Inventory of interpersonal problems: psychometric properties and clinical applications. J Consult Clin Psychol 1988, 56:885-892.

74. Horowitz LM, Strauß B, Kordy H: Das Inventar zur Erfassung interpersonaler Probleme (IIP-64-D) [Inventory of interpersonal problems, German version] Beltz: Weinheim, Germany; 2000.

75. Hatcher RL, Rogers DT: Development and validation of a measure of interpersonal strengths: the inventory of interpersonal strengths. Psychol Assess 2009, 21:554-569.

76. Flückiger C, Caspar F, Grosse Holtforth M: Inventar Interpersoneller Stärken von Hatcher \& Rogers (IIS-64-D). Bern: University of Bern; 2011.

77. Troesken A, Grawe K: Ressourcenpotential und -realisierung für Psychologische Therapie. Verhaltenstherapie \& Psychosoziale Praxis 2004, 36:51-62.

78. Hatcher RL, Gillaspy JA: Development and validation of a revised short version of the working alliance inventory. Psychother Res 2006, 16:12-25.

79. Munder T, Wilmers F, Leonhart R, Linster HW, Barth J: Working alliace inventory-shrt revised (WAI-SR). Psychometric properties in outpatients and inpatients. Clin Psychol Psychother 2010, 17:231-239.

80. Flückiger C, Regli D, Zwahlen D, Hostettler S, Caspar F: Der Berner Therapeuten- und Patientenstundenbogen 2000. Ein Instrument zur Erfassung von Therapieprozessen. Z Klin Psychol Psychother 2010, 39:71-79.

81. Sachse R: Differential effects of processing proposals and content references on the explication process of clients with different starting conditions. Psychother Res 1992, 2(4):235-251.

82. Carver CS: Adult attachment and personality: Converging evidence and a new measure. Pers Soc Psychol Bull 1997, 23:865-883.

83. Hackelöer A, Löwe B, Spitzer C: Die deutsche Version des Measure of Attachment Qualities (MAQ-D): Erste Befunde zu den psychometrischen Gütekriterien. Psychother Psychosom Med Psychol 2009, 59(02):.

84. Sandell R, Carlsson J, Schubert J, Broberg J, Lazar A, Grant J: Therapist attitudes and patients' outcomes. I. Development and validation of the Therapist Attitudes Scales (TASC2). Psychother Res 2004, 14:469-484.

85. Raudenbush SW, Bryk AS: Hierarchical linear models: applications and data analysis methods. 2nd edition. Thousand Oaks, CA: Sage Publications; 2002

86. Faul F, Erdfelder E, Lang A-G, Buchner A: G*Power 3: A flexible statistical power analysis for the social, behavioral, and biomedical sciences. Behav Res Methods 2007, 39:175-191.

87. Baldwin SA, Imel ZE: Therapist effects: Findings and methods. In Bergin and Garfield's Handbook of Psychotherapy and Behavior Change. edn. Edited by Lambert MJ. Hoboken, NJ: Wiley; 2013.

88. Castonguay LG, Goldfried MR, Wiser S, Raue PJ, Hayes AM: Predicting outcome in cognitive therapy for depression: a comparison of unique and common factors. J Consult Clin Psychol 1996, 64:497-504.

\section{doi:10.1186/1471-244X-14-49}

Cite this article as: Flückiger: The adherence/resource priming paradigm - a randomised clinical trial conducting a bonafide psychotherapy protocol for generalised anxiety disorder. BMC Psychiatry 2014 14:49. 